\title{
Old meets new: identifying founder mutations in genetic disease
}

\author{
Jane A. Evans PhD
}

See related research articles on page 102 and at www.cmaj.ca/lookup/doi/10.1503/cmaj.140657 and on page E68 and at www.cmaj.ca /lookup/doi/10.1503/cmaj.140840

$\mathrm{F}$ rom the first arrivals over 10000 years ago to the most recent immigrants, every person coming to Canada has carried with them a unique genetic contribution. Once here, forces such as the size of founder populations and isolation by geography or cultural practices have led to a high prevalence of specific genetic conditions in many diverse ethnic groups. Although an appreciation of such variation in disease frequency and population genetics principles has been around for some time, the application of modern methods for gene identification now has the potential to improve outcomes for patients, their families and communities.

Examples of this approach are well illustrated by two linked $C M A J$ articles. In the first, Macardier and colleagues ${ }^{1}$ document the finding of a common mutation in the $S I$ gene responsible for congenital sucrase-isomaltase deficiency in Inuit, a condition highly prevalent in this population. In the second, Rousseau-Nepton and colleagues $^{2}$ describe the use of whole-exome sequencing in children with glycogen storage disease type IIIa to identify a founder mutation in the $A G L$ gene in Inuit from Nunavik.

Both of these studies deal with autosomal recessive disorders that are common in Inuit populations. Both conditions are caused by homozygous mutations in their respective genes, and yet, despite identical genotypes, affected patients can present with variable manifestations. In both diseases, early diagnosis and dietary interventions may help ameliorate the clinical consequences of the deleterious genotype.

However, although it is apparent that the SI mutation is widespread in Inuit populations, suggesting an ancient origin, the $A G L$ mutation in the Inuit population has so far only been identified in those from Nunavik. Inuit from other regions may also be gene carriers, but the lack of reports of glycogen storage disease type IIIa in other areas $^{3}$ suggests a more recent mutational event. Haplotype analysis can provide information on the relative age of founder mutations, because regions of homozygosity around a gene of interest become shorter with time as a result of meiotic recombination. Furthermore, the $S I$ mutation appears to be unique and restricted to the Inuit, whereas the $A G L$ mutation was found to be the cause of glycogen storage disease type IIIa in a North African Jewish population, ${ }^{4}$ and its heterozygous state has been found in genome databases. Rousseau-Nepton and colleagues suggest that this coincidence is likely due to mutations at a genetic "hot spot" rather than to any shared ancestry. However, introduction of alleles from other groups into indigenous populations is always possible. For example, evidence exists from both molecular data and oral history that the founder mutation for autosomal recessive infantile leukoencephalopathy, seen in Cree and Chippewayan populations in Manitoba and Cree in Northern Quebec, may have come via British fur traders for the Hudson Bay Company in the $1770 \mathrm{~s} .^{5}$

Globally, founder effects have lead to similar patterns of high prevalence of rare diseases in specific populations. Other Canadian examples include infantile hypophosphatasia among Mennonites and Bowen-Conradi syndrome in Hutterites. Founder alleles can also contribute to risk for more common adult-onset disorders. Among the Oji-Cree in northwestern Ontario, a population with high rates of type 2 diabetes mellitus, each copy of a unique mutation in HNFIA

\section{- Ker POINTS}

- Founder mutations are often responsible for the high prevalence of rare genetic disorders in specific populations, but are also associated with more common monogenic disorders and complex traits.

- Awareness of ethnic background allows for targeted screening, but admixture and spontaneous mutation can result in recessive alleles being present in people from populations in which a genetic condition is less prevalent.

- Next-generation molecular techniques have substantially accelerated the finding of rare disease alleles, facilitating diagnosis and treatment and enhancing the provision of personalized genetic health care to patients, families and communities. 
(hepatocyte nuclear factor 1 homeobox A) lowers the median age of onset by about seven years. ${ }^{6}$ Similarly, specific alleles in cancer predisposition genes may be more common in certain ethnic groups, such as $999 \mathrm{del} 5$ in $B R C A 2$ (breast cancer 2, early onset) among Icelandic families with breast cancer ${ }^{7}$ or founder $\mathrm{MSH} 2$ (MutS protein homolog 2) mutations in Lynch syndrome in Newfoundland and Labrador. ${ }^{8}$

Awareness of such variation in distribution of disease has allowed an important preventative health strategy: using ethnic background to identify people who should be offered screening for conditions such as sickle cell anemia, thalassemias and Tay-Sachs disease. Taking a detailed three-generation family history ${ }^{9}$ may provide useful clues as to whether a condition is familial and what the reasons for that might be - genes, shared environment or interactions between them. However, assumptions cannot be made that certain genetic disorders only occur in particular ethnic groups. Cystic fibrosis, although more common in white people, occurs in other populations, such Canadian and Australian indigenous groups owing to either admixture or spontaneous mutation. Qureshi and $\mathrm{Kai}^{10}$ tell a cautionary tale of how ignorance that people with white skin can carry sickle-cell mutations led to delayed diagnosis in an affected child and the erroneous assertion of nonpaternity.

Attention to ancestral background will help assess the probability of genetic disease. In addition, the possibility of parental consanguinity should be explored because it increases risks for both recessive and multifactorial disorders. However, as the linked articles document, in many genetic isolates, close consanguinity is not common, and such populations may in fact be "outbred" (i.e., marriage partners are often less closely related than might happen by chance). Consanguinity increases the likelihood of homozygous genotypes, both wild type and deleterious ones, but it has no impact on allele frequency. Usually, the high prevalence of recessive disease is a consequence of a high carrier frequency due to founder effect and, potentially, heterozygote advantage.

Consanguinity has, however, been very beneficial to the discovery of new recessive mutations using homozygosity mapping. When the culprit gene is already suspected, sequencing may identify the mutation, though this can be challenging, as was initially seen with $A G L$ in the Nunavik population. ${ }^{2}$ Next-generation molecular tools have shown great potential to accelerate discovery in this area, and it should be a source of pride that Canadian initiatives to find mutations for rare genetic disorders (such as the Finding of Rare Disease Genes in Canada [FORGE Canada] Consortium) have been so productive. ${ }^{11}$

As suggested in both articles, once a causative mutation is discovered, opportunities exist to use molecular rather than more invasive diagnostic testing, to start treatment early and to offer carrier testing to family members at risk. In collaboration with the community, targeted population screening can be considered, as has already been done for carnitine palmitoyltransferase I A (CPT1 A) deficiency in Hutterite populations, ${ }^{12}$ the ultimate goal being to reduce the burden of disease and provide patients and their families with more personalized genetic health care.

\section{References}

1. Marcadier J, Boland M, Scott CR, et al. Congenital sucraseisomaltase deficiency: identification of a common Inuit founder mutation. CMAJ 2015; 187:102-7.

2. Rousseau-Nepton I, Okubo M, Grabs R, et al A founder $A G L$ mutation causing glycogen storage disease type IIIa in Inuit identified through whole-exome sequencing: a case series. CMAJ 2015 Jan. 19. [Epub ahead of print].

3. Zimakas PJ, Rodd CJ. Glycogen storage disease type III in Inuit children. CMAJ 2005;172:355-8.

4. Parvari R, Moses S, Shen J, et al. A single-base deletion in the 3 -coding region of glycogen-debranching enzyme is prevalent in glycogen storage disease type IIIA in a population of North African Jewish patients. Eur J Hum Genet 1997;5:266-70.

5. Fogli A, Wong K, Eymard-Pierre E, et al. Cree leukoencephalopathy and CACH/VWM disease are allelic at the EIF2B5 locus. Ann Neurol 2002;52:506-10.

6. Triggs-Raine BL, Kirkpatrick RD, Kelly SL, et al. HNF-10 G319S, a transactivation-deficient mutant, is associated with altered dynamics of diabetes onset in an Oji-Cree community. Proc Natl Acad Sci U S A 2002;99:4614-9.

7. Thorlacius S, Sigurdsson S, Bjarnadottir H, et al. Study of a single BRCA2 mutation with high carrier frequency in a small population. Am J Hum Genet 1997;60:1079-84.

8. Stuckless S, Parfrey PS, Woods MO, et al. The phenotypic expression of three $\mathrm{MSH} 2$ mutations in large Newfoundland families with Lynch syndrome. Fam Cancer 2007;6:1-12.

9. Wattendorf DJ, Hadley DW. Family history: the three-generation pedigree. Am Fam Physician 2005;72:441-8.

10. Qureshi N, Kai J. Genomic medicine for underserved minority populations in family medicine. Am Fam Physician 2005;72:386-7.

11. Beaulieu CL, Majewski J, Schwartzentruber J, et al.; FORGE Canada Consortium. Outcomes of a 2-year national rare-disease gene-discovery project. Am J Hum Genet 2014;94:809-17.

12. Prasad C, Johnson JP, Bonnefont JP, et al. Hepatic carnitine palmitoyl transferase 1 (CPT1 A) deficiency in North American Hutterites (Canadian and American): evidence for a founder effect and results of a pilot study on a DNA-based newborn screening program. Mol Genet Metab 2001;73:55-63.

Affiliation: Biochemistry and Medical Genetics, University of Manitoba, Winnipeg, Man. 